\title{
Preservation Strategies for Geoscience Literature: New Technologies for an Old Literature
}

\section{Lisa A. Wishard and Linda R. Musser}

\begin{abstract}
In this article we describe the complex nature and history of the literature of the geosciences. We evaluate preservation technologies applicable to the formats found in the literature, such as oversize, color, and folded maps and plates. Technologies profiled include deacidification, encapsulation, storage options, and facsimile creation including xerographic, photographic, film, and digital reproduction. We present applications of the technologies and discuss suggestions for developing preservation priorities for the literature.
\end{abstract}

$\mathbf{R}$

esearchers in the geosciences use a wide variety of information sources. While many of these sources are traditional library materials such as journal articles, books, and conference proceedings, geoscientists rely heavily on maps, technical reports, photographs, theses, and dissertations. Consequently, geoscience literature contains complex formats, often combined in a single volume. The frequent presence of folded pages, plates, oversize maps, and illustrations - many in color- makes geoscience materials difficult to preserve using traditional methods. An additional challenge is the value and heavy use of older material in the geosciences. The age of material used in this field is frequently older than in many other fields of scientific research, with materials more than one hundred years old still routinely in use. The complexity

of formats found in the geosciences correspond to the literature of other disciplines, such as art, architecture, and engineering that also frequently use oversize, color illustrations (Commission on Preservation and Access 1992).

In addition to print resources, geoscientists also derive essential information from materials such as geologic specimens, drill cores, well logs, and digital data. North American geoscientists, recognizing the value of these original specimens, have begun an initiative under the auspices of the American Geological Institute to preserve these materials through the National Geoscience Data Repository (American Geological Institute 1998). Similar initiatives to preserve geologic specimens are underway in other countries as well.

Unfortunately, preservation of the traditional print records of geoscience

LISA A. WISHARD (lawisha@sandia.gov) is senior technical information specialist, Technical Library, Sandia National Laboratories, Albuquerque, and LindA R. MUSSER (lrm4@psu.edu) is head, Earth and Mineral Sciences Library, Pennsylvania State University, University Park. Manuscript received December 7, 1998; accepted for publication February 5, 1999. 
knowledge has not received the same attention from the library community. In the U.S., national libraries such as the National Agricultural Library in agricultural sciences and the National Library of Medicine in the medical sciences have taken the lead in preserving the literature of several scientific fields. The U.S. has no national library devoted to the geosciences, however, and the U.S. Geological Survey Library, viewed by many as the de facto national geosciences library, has no established preservation program (Wishard 1999; Klimley 1984).

In this paper, we will look at the physical characteristics of geological literature, review past practices in preserving the geological literature, and examine advances in preservation technologies that are being applied to geoscience materials today. We will also profile several preservation projects in the geosciences and, finally, discuss the preservation initiatives of the Geoscience Information Society.

\section{Development of Geoscience LITERATURE IN NORTH AMERICA}

Prior to 1823 , geological research in the Americas appeared primarily in journal articles and monographs. In 1823, the first geological survey was conducted in North Carolina. Over the next 77 years, nearly 40 states, territories, and provinces followed suit so that, by the end of the century, the state and provincial geological survey had become a permanent part of many local governments. The $1800 \mathrm{~s}$ saw increases in the amount of geoscience publications - not only in serials but also in the reports and volumes published by geological surveys (Stoffer 1988; Hazen 1980; Meadows 1974). By the 1850s, there were more than 50,000 pages published in the geoscience literature, primarily in serial publications (Menard 1971). During the next century, however, there was even greater growth in the number of publications in the field, with more than one million pages in print by 1950 (Menard 1971). Significantly, the majority of the publications published during this period were geologic surveys, which by the mid-nineteenth century out- numbered serial publications (Menard 1971).

The primary purpose that geologists had in the early period was to promote economic development through identification of useful mineral deposits. Much of their work remains relevant today and is routinely used by practicing geologists and engineers. Additionally, these early publications contain information on the growth and commerce of towns and cities, development of industries, details of Native American life and of other residents, and descriptions of local flora and fauna. Not surprisingly, today's users of the early geological literature of North America include not only geologists and engineers but also genealogists, historians, geographers, biologists, anthropologists, and others.

These early publications contain a variety of formats-text, maps (both color and black and white), photographs, and color illustrations. Scott $(1993,83)$ stated that geology was "one of the earliest sciences to employ color to encode information. Text cannot adequately describe, for example, the detailed and often complex subsurface relationships of stratigraphic formations without complementary illustrations." Klimley (1984) considered the heavily and variously illustrated geological publications of the nineteenth and twentieth century to be a worst-case scenario for application of preservation techniques. In addition, between 1850 and 1950 - the era of highly acidic paper use-there was huge growth in the number of geological science publications. This is readily apparent upon examination of many of these documents, which exhibit the telltale signs of acidic paper-brittle, yellowing pages. Thus we have the current situation, in which early geosciences literature is increasingly useful to a broad range of users while the material itself is increasingly fragile and difficult to preserve.

\section{Historic Geoscience Literature Preservation Techniques}

To date, traditional preservation techniques have been applied to geoscience literature with some success. For exam- 
ple, the collection of Sir William Logan, first director of the Geological Survey of Canada, received treatment on a volumeby-volume basis using deacidification and encapsulation in the collections of the Geological Survey of Canada (Kamel 1998). In many libraries, deteriorating materials have been rebound or placed in storage boxes. In other cases, folded maps have been unfolded and stored flat in attempts to reduce wear and breakage along fold lines.

Microfilming has been used as a preservation technique since the mid-1800s (Luther 1959), but difficulties related to use of color and the ability to film oversize images is still considered problematic for the geosciences. Most geoscience publications that have been microfilmed to date have been captured in black and white, resulting in the loss of the full integrity of many of the images. Examples of collections preserved in this way include the UMI collection of dissertations, theses, and miscellaneous geoscience serials, the American Natural History 1769-1865 microform set by Primary Source Media, and the Landmarks of Science series by Newsbank. The lack of color in this preservation process is extremely serious as most geologic maps use color to differentiate geologic formations from the underlying details of the base map. Scott's (1993) evaluation of UCLA geology thesis and dissertations found that $52 \%$ of the maps and plates evaluated were in color and used color to encode information. Additionally, in these collections, oversize maps were generally microfilmed in pieces so that only portions of the map can be viewed at a time, thus obliterating the overall characteristics or trends depicted in the original piece (Klimley 1984).

The preservation efforts undertaken thus far have affected only a tiny fraction of the geological literature requiring attention. Therefore, while there have been notable efforts to date, the bulk of preservation work of the geological literature lies ahead.

\section{Current Preservation Strategies}

The advent of improved technologies for color copying and new digitizing technol- ogies provides methods for the reformatting and replacement of color and large size maps and illustrations. These, in conjunction with well-established preservation technologies such as deacidification and encapsulation, provide librarians with a wide range of tools necessary to preserve the geological literature. We will describe each of these technologies in reference to its use in preserving the geological literature. First, we will describe methods that focus on the preservation of the original document. Then we will discuss methods that preserve the content of the document.

\section{DEACIDIFICATION}

Paper that is safely buffered and housed in a proper environment can last hundreds of years. The goal in deacidification is to absorb or reduce the acidic levels in existing paper publications to permit a longer shelf life. The process halts further acid damage but does not repair or improve the extant condition of the item. Deacidification does not remove the acid from the paper, nor does it strengthen brittle paper. In the process, the acid in the paper is chemically neutralized, which provides a chemical reserve that serves as a buffer for the paper fibers against future acid attacks. Deacidification can be a viable volume-by-volume treatment alternative for geoscience material.

Mass deacidification is the process by which batches of volumes are treated in a large treatment chamber. Several methods have been developed. In one of the more commonly used processes, volumes are immersed in a bath of alkaline submicron magnesium oxide particles for approximately 25 minutes. While in the bath, the volumes are agitated to increase contact of the pages with the magnesium oxide. Volumes are then dried in an evaporator chamber for several hours (Domach 1997; Dalrymple 1997). The use of mass deacidification has not been widely applied due to the perceived complexity of treating the multiformat geological literature.

In several pilot applications to geological collections, however, researchers suggest that mass deacidification is a viable 
preservation option for this literature. Wick (1993) evaluated a 1992 mass deacidification process applied to separate maps, theses, and serial volumes with folded maps from the Harvard Kummel Geological Sciences Library collection and judged it to be satisfactory, with most volumes being successfully treated. Wick noted that there were some instances of color shifting on photographic plates and on folded maps within serial volumes, although colored plates and flat maps (including those that were hand colored) exhibited no shifts in color and were judged satisfactory. Gaydos (1998) found that during a recent trial at Pennsylvania State University, deacidification was successfully applied to volumes of clay-coated paper. Treated volumes were found to have an acceptable level of alkaline reserves. In a test of the volumes, Preservation Technologies, L.P., found alkaline reserves of $1.9 \%$, in comparison with reserves of $0.6 \%$ found on similarly treated books from the Library of Congress.

The mass deacidification process provides a tool by which collections can be preserved in large quantities. Extra deliberation should still be applied, however, when brittle volumes with folded and photographic plates-items prevalent in collections of geologic material-are selected for mass deacidification. It should also be noted that acidic paper, even after deacidification, will be weaker than nonacidic paper and might require careful handling or reinforcement, such as binding or encapsulation.

\section{ENCAPSULATION}

Encapsulation is a commonly used technique to preserve sheet materials such as maps and illustrations. The sheet is placed between two pieces of polyester mylar. The edges are then sealed with an ultrasonic weld or with acid-free, doublesided tape. Gaps are left in the corners of the seal so that the piece can breathe. The static charge between the two sheets of mylar keeps the piece stationary and will actually hold together items that are in multiple pieces. Caution should be used when encapsulating hand-colored items, however, because "particles of color can be removed by the electrostatic charge which is created between the two sheets of mylar" (Scott 1993, 84). Mylar is an inert, inflammable material that has been subjected to many rapid-aging tests and has a life expectancy of several hundred years. The mylar enclosure reinforces the encapsulated piece so that even previously brittle material can be used with ease. Encapsulation is used to preserve both acidic and acid-free print materials. In some cases, for single-sided materials, a buffered alkaline paper backing can be inserted behind the piece in order to absorb some of the acid from the encapsulated item.

Encapsulation is one of the primary methods recommended for preservation of maps and oversize plates in their original form. Maps and plates that have been folded in a text block must be unfolded prior to encapsulation. Once encapsulated, maps should not be folded or refolded. Encapsulation is a very effective method for preserving an original, though it can limit the use of a piece. For instance, once a map is encapsulated it becomes quite cumbersome to take into the field for active use-a common practice in the geosciences. In addition, encapsulation can also create problems when encapsulated items are separated from their explanatory and other accompanying materials.

Encapsulation has been used in many collections. Allen (1990) describes the New York Historic Map Preservation Project, where nearly 2,000 maps-primarily transportation and topographic maps on a variety of media, including wall, rolled, blueprint, and other various printed maps-were cleaned, deacidified, and encapsulated. Newman $(1987 ; 1998)$ outlines how thesis and dissertation maps are cleaned and encapsulated at the DeLaMare Library of the University of Nevada, Reno. In an example of encapsulation and binding, staff at Pennsylvania State University Libraries deacidified, encapsulated, and post-bound $29 \mathrm{vol}$ umes related to Pennsylvania from the Geologic Atlas of the United States (Wishard 1999). 


\section{ENVIRONMENTAL AND STORAGE OPTIONS}

The physical environment in which a piece is stored can also affect its longevity. Often out of the direct control of facilities managers, and not seen as glamorous to discuss (Wick 1991), collections are often imperiled by their very surroundings--by leaking labs, temperature and humidity fluctuations, etc. In addition to protecting against the physical climate of collections, storage of items in acid-free housings such as phase boxes and folders can help to diminish the cumulative deterioration of acidic paper. Certainly, properly sized shelving and map cases are important to ensure the longevity of materials. Archival storage of less frequently used and unique materials in a climate controlled facility can also help to preserve material.

\section{Facsimile Creation}

The creation of facsimiles is a timehonored method for preserving the intellectual content of publications. Facsimile production is necessary to maintain access to information that might be stored in an inaccessible original medium. Until recent years, the primary methods available for facsimile creation were black and white photocopy reproductions or reproductions from monochromatic film. Photographic reproduction was also an option, albeit an expensive one. New technologies such as color photocopying, color microfilming, and digital scanning now offer additional possibilities for facsimile creation. These new facsimile technologies-which preserve extant volumes of varied mediums such as text, maps, and images-allow researchers to work with the full intellectual content of a piece as well as see the context of the material in its original format (Klimley 1984 and 1995; Gertz 1996).

\section{Xerographic and Photographic Facsimiles} Xerographic reproduction has been used successfully for many years to create facsimiles. Baird (1997) described Project Brittle, an example of a cooperative effort to use preservation photocopy technology to replace worn original material. The only limitation of this technique has been the in- ability to reproduce color. Color photocopy technology has advanced in recent years, however, such that inexpensive reproductions of standard-sized color pieces can be successfully produced that can allow the possibility of piecing together oversize items (Newman 1998; 1989).

Photographic facsimiles are extremely effective for reproducing details and colors of original documents, especially in oversize images. This technique's primary drawback is its expense. While a photographic negative can be created at a reasonable cost, a print of an oversize image can be quite expensive.

\section{Film Facsimilies}

Microfilm remains the primary archival medium for text-based materials. Microfilm stored in ideal conditions can survive for half a millennium or more and would still be accessible with only candlelight and good eyesight, compared to the short useable life span of only 5 to 10 years for digitally stored materials (Conway 1996). However, producing high quality film images of oversize material still poses difficulties. If a large image can be captured in a single frame, the fine details such as roads, place names, and legends are often unreadable. Similarly, images sectioned onto several frames are often deemed unusable (Gertz 1996). The use of color in microfilming has, however, been successfully addressed (Klimley 1993; Newman 1989), despite the fact that capturing oversize images on single frames still proves problematic. Color microfilm technology has been successfully applied to color oversize images at Columbia University as part of the New York State Bulletin project (Gertz 1997) and at the Hargett Library at the University of Georgia (Henneberger 1994), where film images were used as a transition medium for creating digital copies of oversize images.

\section{Digital Facsimiles}

Developments in digital reproduction technologies have broadened facsimile creation options. Today, digital cameras and scanners allow the full integrity of the geologic original, including color, to be reproduced. The digital images can then be printed with color printers, plotters, 
and photocopiers with nearly indiscernible differences in color from the original. In fact, the Commission on Preservation and Access $(1992,12)$ stated that there are "striking examples of visual material that has been digitized and subsequently reproduced in paper copy, sometimes clearer and more legible than the original document from which the digital copy was made."

The ability to produce digital facsimiles has increased the options for preserving the oversize media prevalent in the geological literature. These developments allow librarians to make preservation decisions based on the condition and content of material rather than by the limitations of traditional preservation options (Gertz 1996). These new digital options are especially relevant in relation to geologic maps and other oversize plates that have used color to encode the complex information that they depict.

Digital copies of materials can be stored as bitmapped images on a variety of magnetic and optical storage devices such as diskette, tape, or CD-ROM. Contemporary color technologies are well suited for reproducing geologic images on screen as well as in print. Digital reproductions of geologic images are viable at much lower resolutions than in many other fields (Gertz 1996; Commission on Preservation and Access 1992) because there typically only needs to be a discernible difference in color rather than reproduction of the fine color details. Satisfactory results have been achieved on pilot projects at Pennsylvania State University and other institutions (Allen 1998) using 24-bit true-color matching at 300 dots per inch (dpi) resolution as well as with 256 no-color matching at the same resolution. Gertz $(1996 ; 1997)$ and Klimley (1993) examined the quality of digital images of the New York State Museum Bulletin and found acceptable resolutions at less than 300 dpi for oversize images. Allen (1998) profiled additional digital projects that suggest similar results, though he stated, "These efforts $\ldots$ have as yet led to no consensus as to whether it is really necessary to scan master images at a higher resolution than 300 dpi in 24-bit color, and no agreed upon minimum resolution for such archival images appears to be emerging."

Geological material has been digitally reproduced with a variety of techniques at different institutions. Heiser (1998) reported on a project at Indiana University in which early survey material for the state was scanned and stored as text files. Trombatore (1998) described a project in which documents at the University of Texas were scanned and stored as digital images of the actual page. At Washington University, a 1928 thesis was digitally reproduced by rekeying the text and scanning the images (McLeod 1998). Digital reproduction of oversize images has been explored at the Library of Congress (Fitzpatrick 1997), the United States Geological Survey (U.S. Geological Survey 1998), and the Virginia Board of Public Works (Library of Virginia 1998), among others.

Preserving material in a digital format is an attractive option because the captured image can be made accessible to a wider audience. However, the need of geoscientists to be able to take the material into the field can not be forgotten, so mechanisms for delivery of hard copy reproductions should be incorporated into any program to digitally preserve geologic material. In addition, the longevity issues raised by Conway (1996) remain problematic, as does the repeated and systematic refreshing (Commission on Preservation and Access 1992) that this transitory nature requires. The challenge of preserving information in electronic format cannot be overlooked. While digital technologies offer exciting new options for preservation, they pose new challenges for long-term retention and storage. Discussion of these challenges fall beyond the scope of this paper, however, and are covered well elsewhere in the literature (Allen 1998; Conway 1996; Klimley 1995; Rothenberg 1999).

\section{Prionities for Preservation}

Many of the projects profiled here are pioneering in scope and focus and in the use and development of new preservation methods. This work raises awareness of 
the needs of preservation for the varied formats of information found within the geoscience field. In many of these projects, the accessibility and breadth of preservation techniques available to collection managers has also been demonstrated.

Such experiments in using these new technologies bode well for the future preservation of the geological literature. Indeed, one of the primary challenges facing geoscience librarians is not only to become educated regarding these technologies but also to raise awareness among their colleagues and the producers of the information that it is, at long last, possible to preserve this literature in all its facets-color, oversize, plates, etc.

In order to facilitate this process, the Preservation Committee of the Geoscience Information Society (GIS) (1997) summarized the challenges of preserving this literature and called for the development of a systematic international initiative to preserve the geoscience literature.

DeFelice (1990) surveyed 107 librarians and found that $51 \%$ of the respondents indicated a willingness to participate in a cooperative preservation project. Wishard (1999) surveyed librarians at 489 libraries and found that less than half of the respondents had active preservation programs, and even fewer had preservation officers at their institutions. DeFelice found that there was no overall consensus on the question of the type of material that would need or will need preservation the most. Journals and folded maps were ranked highest, followed closely by books, flat maps, U.S. Geological Survey documents and theses, and thesis maps. Wick (1991) found that more than $70 \%$ of the respondents indicated some geographic designation-such as regionally, by country or state-to define how they choose candidates for preservation. Wishard (1999) found that when respondents were asked to identify geoscience literature most at risk and in need of preservation treatment, they ranked historic geologic maps as the highest priority for preservation treatment, followed by pre-1900 material. When asked to identify a focus for a preservation plan, most respondents indicated a preference for a geographic emphasis.

The continuing activities of the GIS Preservation Committee include coordinating preservation projects and acting as a clearinghouse that documents projects where geoscience literature has been preserved. In addition, the committee hopes to continue to demonstrate capabilities and raise awareness regarding the possibilities of preservation technologies for geoscience material.

\section{Conclusion}

Ultimately, however, the preservation of the geological literature rests in the hands of the many librarians around the world working with this literature as well as those producing the literature. Publishers need to develop standards for future geoscience publications to use preserva- tionally sound material such as acid-free paper and digital formats that can be easily migrated, and apply such basic principles as limiting the size of maps and plates in theses and other publications (Newman 1998). Similarly, librarians need to develop priorities for preserving the material in their geoscience collections. Geoscience librarians need to move beyond the volume-by-volume approach to preserving their collections and realize that there are many viable and sophisticated means to preserve and conserve the literature of the geosciences. Publishers and librarians must work together to establish standards and priorities in order to ensure the survival of the geoscientific literature for future generations.

\section{Works Cited}

Allen, David Y. 1990. Preserving maps in quantity: The experience of the New York State Historic Map Preservation Project. Meridian 4: 29-35.

. 1998. Creating and distributing high resolution cartographic images. Research $\mathrm{Li}$ braries Group DigiNews 2, no. 4. Available at: http://www.rlg.org/preserv/diginews/ diginews2-4.html. Accessed: November $13,1998$.

American Geological Institute. 1998. National Geoscience Data Repository System. Available at: http://www.agiweb.org/NGDRS/. Accessed: November 13, 1998. 
Baird, Brian. 1997. Brittle: Replacing embrittled titles cooperatively. College and research libraries news 58: 83-84, 95.

Commission on Preservation and Access. 1992. Preserving the illustrated text: Report of the joint task force on text and image. Available at: http://www.clir.org/pubs/ reports/presillu/presillu.html. Accessed: November 13, 1998.

Conway, Paul. 1996. Preservation in the digital world. Microform and imaging review 25: 156-71.

Dalrymple, Will. 1997. A paper chase: Technology helps library save its collections on paper. Library of Congress information bulletin 56: 148-51.

DeFelice, Barbara. 1990. Cooperative collection development and preservation projects in the geosciences. In Proceedings of the twenty-fourth meeting of the Geoscience Information Society, St. Louis, Mo., November 6-9, 1989, ed. Mary B. Ansari, vol. 20: 63-74. Alexandria, Va.: Geoscience Information Society.

Domach, Michael M. 1997. Technical evaluation of PTI mass deacidification technology. Available at: http://palimpsest.stanford. edu/byorg/lc/massdeac/domach.html. Accessed: June 25, 1998.

Fitzpatrick, Gary L. 1997. Digital program of the Geography and Map Division, Library of Congress. In Proceedings of the thirtysecond meeting of the Geoscience Information Society, Salt Lake City, Utah, October 19-23, 1997, ed. Connie J. Manson, vol. 28: 67-70. Alexandria, Va.: Geoscience Information Society.

Gaydos, Robert M. 1998. Letter to Sue Kellerman, October 8.

Geoscience Information Society. Preservation Committee. 1997. Action plan for the preservation of geoscience literature. Available at: http://www.libraries.psu.edw emsl/guides/gis/gispcplan.html. Accessed: November 18, 1998.

Gertz, Janet. 1996. Selection for preservation: A digital solution for illustrated texts. $\mathrm{Li}$ brary resources and technical services 40 : 78-83.

1997. Oversized color images: Addressing issues of preservation and access. Available at: http://www.columbia.edu/dle/ nysmb/reports/phasel.html. Accessed: November 18, 1998.

Hazen, Robert M., and Margaret Hindle Hazen. 1980. American geological literature, 1669-1850. Stroudsburg, Pa.: Dowden, Hutchinson, and Ross.

Heiser, Lois. 1998. Preservation activities at
Indiana University. Geoscience Information Society newsletter 170: 8.

Henneberger, Bob. 1994. Preservation and access of rare maps at the University of Georgia Libraries. Microform review 23: 169-71.

Kamel, Pauline. 1998. Geological Survey of Canada Logan Legacy Fund. Geoscience Information Society newsletter 174: 10.

Klimley, Susan. 1984. Preservation options for geology serials containing maps. In Proceedings of the nineteenth meeting of the Geoscience Information Society, Reno, Nev., November 5-8, 1984, ed. Claren Kidd, volume 15: 52-58. Alexandria, Va.: Geoscience Information Society.

__ 1993. Notes from the cutting edge. Microform review 22, no. 3: 105-7.

- 1995. Digital preservation: The promise vs. the reality. In Proceedings of the thirtieth meeting of the Geoscience Information Society, New Orleans, La., November 5-8, 1995, ed. Nancy L. Blair, volume 25: 5-9. Alexandria, Va.: Geoscience Information Society.

Klimley, Susan, et al. 1997. Integration of text and image in the digital book format. In Proceedings of the thirty-first meeting of the Geoscience Information Society, Denver, Colo., October 28-31, 1996, ed. Barbara DeFelice, volume 27: 57-61. Alexandria, Va.: Geoscience Information Society.

Library of Virginia. 1998. Board of Public Works inventory. Available at: http:// 198.17.62.51/BPW/. Accessed November $13,1998$.

Luther, Frederic. 1959. Microfilm, a history, 1839-1900. Annapolis, Md.: National Microfilm Association.

Meadows, A. J. 1974. Communication in science. London: Butterworths.

Menard, Henry W. 1971. Science: Growth and change. Cambridge, Mass.: Harvard University Press.

McLeod, Clara P. 1998. Conversation with authors. Toronto, Ontario, Canada. October 27.

Newman, Linda. 1987. Map preservation: The Mackay School of Mines thesis project. Western Association of Map Libraries information bulletin 19, no. 1: 5-7.

-1 1989. Color photocopying to reproduce/preserve geologic maps in literature. In Proceedings of the twenty-third meeting of the Geoscience Information Society, Denver, Colo., October 31-November 3, 1988, ed. Joanne V. Lerud, vol. 19: 205-8. Alexandria, Va.: Geoscience Information Society.

- 1998. Thesis preservation project at the Mines/DeLaMare Library, University 
of Nevada, Reno. Geoscience Information Society newsletter 171: 12-13.

Rothenberg, Jeff. 1999. Avoiding technological quicksand: Finding a viable technical foundation for digital preservation. Washington, D.C.: Council on Library and Information Resources. Also available at: http://www.clir. org/pubs/reports/rothenberg/pub77.pdf.

Scott, Sally J. 1993. Preservation needs of oversized illustrations in geology master's theses. Library resources and technical services 37: 73-85.

Stoffer, Phil W. 1988. The proliferation of geological societies and their impact on the geological information explosion. In Proceedings of the twenty-second meeting of the Geoscience Information Society, Phoenix, Ariz., October 26-29, 1987, ed. Jean T. Eaglesfield, vol. 18: 129-55. Alexandria, Va.: Geoscience Information Society.

Trombatore, Dennis. 1998. Creating a digital archive on the geology of Texas. Geoscience Information Society newsletter 172: 8.

United States Geological Survey. 1998. National Mapping Information. Available at: http:// mapping.usgs.gov/. Accessed: November 18, 1998.
Wick, Constance S. 1991. Preservation of geoscience library collections: Current conditions and future trends. In Proceedings of the twenty-fifth meeting of the Geoscience Information Society, Dallas, Texas, October 29-November 1, 1990, ed. Marie Dvorzak, vol. 21: 147-53. Alexandria, Va.: Geoscience Information Society.

Wick, Connie S. 1993. Image-related aspects of preserving high-use geoscience literature by deacidification. In Proceedings of the twenty-seventh meeting of the Geoscience Information Society, Cincinnati, Ohio, October 26-29, 1992, ed. Louise S. Zipp, vol. 23: 5-10. Alexandria, Va.: Geoscience Information Society.

Wishard, Lisa. 1999. Activities of the Geoscience Information Society Preservation Committee. In Science editing and information management: Proceedings of the second international AESE/CBE/EASE joint meeting, sixth international conference on geoscience information, and thirty-second annual meeting, association of earth science editors, Washington, D.C. September 10-14, 1998, ed. Connie J. Manson: 43-49. Alexandria, Va.: Geoscience Information Society. 